\title{
Internationalization, Deregulation and the Extension of Higher Education in Korea: A Further Note
}

\author{
Jang C. Jin ${ }^{1}$ \\ ${ }^{1}$ Department of Economics, George Mason University - Korea, Incheon Global Campus, Songdo, Incheon, South \\ Korea \\ Correspondence: Jang C. Jin, Department of Economics, George Mason University - Korea, Incheon Global Campus, \\ Songdo, Incheon, South Korea. Tel: 82-32-626-5103 E-mail: jjin7@gmu.edu \\ Received: July 29, 2015 \\ Accepted: August 11, 2015 \\ Online Published: August 17, 2015 \\ doi:10.5430/ijhe.v4n3p156 \\ URL: http://dx.doi.org/10.5430/ijhe.v4n3p156
}

\begin{abstract}
The Korean government implemented several educational policies to enhance internationalization of higher education such as deregulation of higher education, classroom instructions in English, and faculty publications in international refereed journals. However, the speed of globalization has been lagging behind (Green, 2015). Alternatively, this Note suggests the merit of off-shore campuses that educate students globally and upgrade higher education nationwide. Inviting off-shore campuses from overseas would be a cost- effective way to boost internationalization of domestic higher education.
\end{abstract}

Keywords: Off-shore campus, Internationalization, Higher education, Korea

\section{Introduction}

Recently, Green (2015) reviewed the historical aspects of internationalization of higher education in Korea and found that the speed of globalization has been slower than expected. More specifically, the Korean government deregulated higher education to enhance internationalization in the 1980s and 1990s, but this caused the number of universities and colleges doubled. In contrast, the birthrate has declined over time, and thus high school graduates will soon be less than college admission quotas (Green, 2015, Table 3). The resulting overcapacity, in general, lowered the quality of higher education in Korea (Shin, 2015). The flow of domestic students to foreign universities also caused a 'brain drain' to be more serious than ever (Choi, 2013). Hence, Korean universities implemented several instruments to be competitive with overseas universities. For example, classroom instructions in English aimed to educate students globally. Faculty's publications in international refereed journals also intended to promote transnational collaboration of research in a more universal scientific language, such as English. However, the internationalization of higher education in Korea has suffered from linguistic obstacles, and the speed of globalization is lagging behind, perhaps, due to cultural and socioeconomic reasons.

Alternatively, inviting off-shore campuses from overseas would be a cost-effective way to educate domestic students globally (Wilkins \& Huisman, 2012, among others). Incheon Global Campus (IGC) in Korea is one example. The IGC currently includes four foreign universities, and six more universities overseas will participate in the future (IGC Foundation, 2015). In addition to IGC's cost-reducing benefits and course-sharing advantages among participating universities (Schiller \& Park, 2014), another important merit of the IGC would be the spillover effects of internationalization on higher education in Korea. At the IGC, instructions are all in English and students are educated to enrich global leaderships. To keep the prestige of parent universities, off-shore campuses also maintain research engagements globally. The high standards of education at the IGC will then spread out to local universities, which will eventually advances higher education in Korea. (Note 1) Although several educational policies were evaluated in Green (2015), the important role of offshore campuses in internationalization did not go into detail. This note thus fills the gap, using branch campus students' learning effectiveness that can be perceived through the number of research-active faculties at parent universities.

\section{IGC as a Case Study}

The Incheon Global Campus (IGC) was recently established at Incheon, Korea, aiming to upgrade higher education in Korea (IGC Foundation, 2015). Unlike local universities, faculty members are recruited directly from main campuses in the United States and European countries, and students who enroll are diverse from all over the world. 
So far, four universities were invited from overseas: George Mason University (USA), Ghent University (Belgium), State University of New York at Stony Brook (USA), and University of Utah (USA). Each university started with a small number of departments that are best representatives of a home university, and some of them are known as the top tier in world rankings. There is no duplicate of similar departments among participating universities and hence unnecessary competitions are designed to be avoided (IGC Foundation, 2015). If all these branch campuses are combined horizontally under the IGC umbrella, it will facilitate collaboration among participating universities and hence cost-reducing benefits are another merit of the IGC. If inter-university credit transfers are allowed, course-sharing among participating universities will also help students select more courses flexibly.

In addition, the horizontal combination of all participating universities at the IGC that consists of 30-40 departments has a strong potential to rank number one as a research university in Korea. George Mason University in Korea ('Mason Korea') that was born small in spring 2014 is a typical offshore campus at the IGC. Focusing on undergraduate education of three departments (economics, global affairs, and management), Mason Korea has a distinctive degree program such that students are required to go to the main campus and must survive there for two semesters. Main campus faculties also visit for one or two semesters to teach at Mason Korea. In this way, Mason Korea students normally take courses directly from parent university faculties until they graduate. Accordingly, students' learning effectiveness at Mason Korea is more or less equivalent to the learning effectiveness of main campus students.

Of course, taking courses may not be all of what students wanted to learn while in school, but Mason Korea students learn from more research-active professors, compared to local universities in Korea. More specifically, faculty member's research outputs of George Mason University (GMU) is directly compared with research publications of Seoul National University (SNU) a best known university in Korea. The two schools are compared in terms of research productivity since more important in the effectiveness of student's learning would be the excellence of faculty. This is similar to the case that best sports players in Olympic Games are raised up most likely by best coaches (IOC, 2015).

Figure 1 shows the research outputs of both business and economics departments in two universities: GMU vs. SNU. The bar graph indicates the number of research papers published by affiliated faculty members at the time of publication. Since faculty members move from time to time, the measurement of publication used here indicates how productive their current and past faculty members were. The publication data were obtained from the search engine Web of Science (April 2014) that includes SSCI (Social Science Citation Index) publications in both business and economics, and author affiliations are available from 1980.

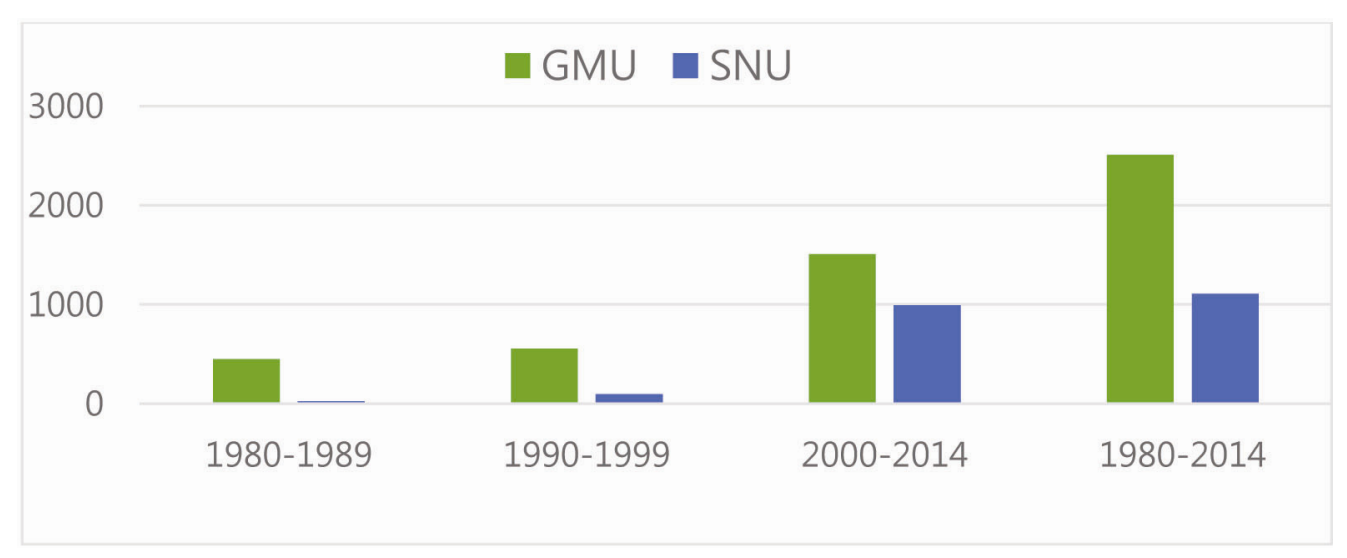

Figure 1. Publications by Affiliated Faculty at the Time of Publication: Business \& Economics

Source: Web of Science (April 2014)

In the decade of the 1980s, GMU published 449 papers, while SNU was almost inactive (24 papers) at the time. Similar trends were observed in the 1990s: GMU (553 papers) published slightly more than before, yet SNU (93 papers) remained sluggish. In the 2000s, GMU (1506 papers) and SNU (992 papers) both improved a lot (about 3 and 10 times, respectively). The sizeable increase in SNU was largely attributed to 'imported publications' from overseas (Jin, 2009). In particular, many prolific Korean professors overseas especially from the U.S. and European countries moved to SNU in the early 2000s. The enlarged publication also matches with the gradual increase of 
globalization in the 2000s in Korea. (Note 2) Their total publications over the entire sample period (1980 to early 2014) were, however, less than half of GMU publications.

Figure 2 shows the research productivity of economics department only. Again, the bar graph indicates the publications by affiliated faculty at the time of publication. In this case, another search engine EconLit (April 2014) was employed to crosscheck the number of publications (Note 3). Author affiliations are available from 1990. Again, the SNU economics department (115 papers) published significantly lower than GMU economics department (425 papers) in the 1990s, but began to catch up in the 2000s. Over the entire sample period 1990-2014, GMU publications were, again, more than double the SNU publications.

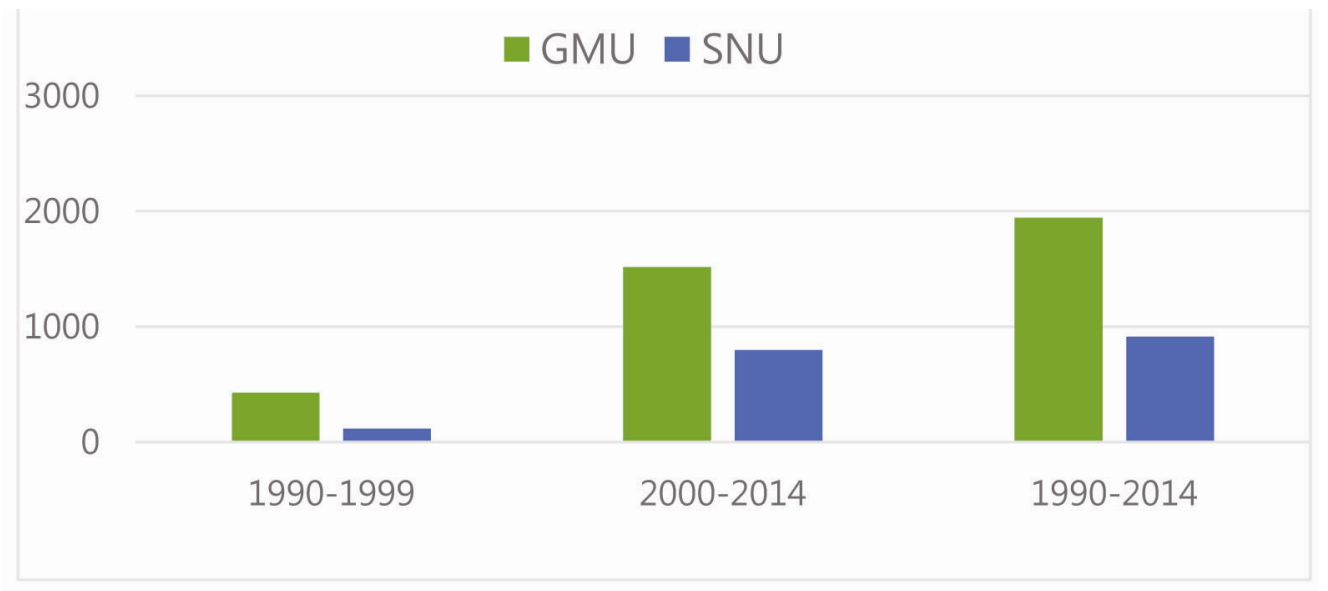

Figure 2. Publications by Affiliated Faculty at the Time of Publication: Economics

Source: EconLit (April 2014)

For the robustness of the results, Table 1 further counts all records of publications in economics for current faculty members rather than past faculties. Current team players are more important in any sports league to maintain team reputations. Likewise, the list of current faculty members were obtained from each school website (as of spring semester 2014). For each faculty member, EconLit (April 2014) was used to search for her/his publications.

Table 1. Publications by Current Faculty Members

\begin{tabular}{lll}
\hline Department of Economics & GMU & SNU \\
\hline Number of Faculty Members: & 41 & 37 \\
Total Number of Publications: & 1,069 & 531 \\
Publications per capita: & 26 & 14 \\
\hline
\end{tabular}

Source: EconLit (April 2014)

Although many prolific scholars overseas moved to SNU noticeably in the past decade, their total number of publications is still about a half of the GMU economics department. Departmental sizes are similar to each other, but SNU's per capita publication turns out to be approximately one half of the GMU economics department. In other words, the research productivity of one typical GMU faculty in economics is about double the productivity of a typical SNU faculty in economics.

\section{Discussion and Conclusions}

The case study suggests that even a best known university in Korea is relatively short of research publications, compared to a typical state university in the U.S. The results are, in general, consistent with the findings in Jin (2009) in which Korean top-tier universities published less than major state universities in the U.S. and their total publications are less than in Hong Kong, Singapore, and Japan. The results are further supported by the finding in Jin \& Cho (forthcoming) that only a dozen research schools in Korea published in international journals, but many second-tier universities published more in domestic journals that uses the Korean language. This suggests that Korean universities, in general, are less competitive internationally. The less competitiveness is, perhaps, due to a rigid higher education system in Korea that is less open and less internationalized (Green, 2015).

In contrast, recently introduced branch campuses from overseas that are well equipped with productive faculties at 
parent universities educate students globally. The merits are twofold. First, the medium of instruction is $100 \%$ in English. Students are trained to discuss fully in English. Of course, the classroom instruction in English was not new in Korea. It was first ever tried at local universities for one or two selected courses as early as in the 1970s, but the progress was not successful at the time since students were unfamiliar with lectures in English. Korean faculties were not comfortable with teaching in English as well. Recently, more courses have used English as a medium of instruction but the purpose of internationalization was limited to be achieved. More important was the quality of learning. Since then, English has been seldom used as a medium of instruction at local universities, except a few, in Korea. However, this language barrier is no longer a serious problem at international branch campuses because students, as well as faculties, have learning experiences from overseas. All lectures are conducted in English and, for creative thinking, students are allowed to discuss freely in English. After being learned in English, students at offshore campuses are able to understand domestic issues more objectively from a foreigner's point of view. Learning in English also facilitates students to understand global issues better.

Another merit of international branch campuses is an enhancement of good working environments at small 'liberal arts college' type universities. Unlike big local universities, offshore campuses start with a small number of departments and hence the student-faculty ratio is normally small. Such a cozy environment allows students to contact with faculties more frequently and gives students more opportunities for independent research. Especially, undergraduate research is difficult to be done at big local universities. However, small offshore campuses provide opportunities for undergraduate students to work with faculty members for academic research as much as possible. Students are also enabled to write research papers in English for global recognition of academic research. Creative thinking is another big advantage of learning at offshore campuses. Overall, students' learning effectiveness at international branch campuses will be greater than at local universities in Korea.

This upshot is based on the presumption that all students at off-shore campuses get similar benefits from their parent university faculties who are academically more prolific than in local universities in Korea. Such merit continues as long as high standards of quality education at off-shore campuses are maintained. In particular, branch campus students are trained to be globalized with fluent English speaking and enriched global leaderships. While freshmen are a bit awkward in this exotic study environment, students in four years will have more confidence in understanding domestic and global issues. Their job markets are no longer domestic. All these benefits are the rewards that students deserve from four-year education at offshore campuses.

To sustain high standards of education, faculty members are also emphasized to publish in international refereed journals. The need to publish in English has been emphasized for global recognition of academic research (Altbach, Reisberg \& Rumbley, 2009, among others). The prominent role of the English language these days is due to globalization that has profoundly influenced higher education (Findlay \& Tierney, 2010, among others). Professors' publications are also found to play a significant role in economic growth (Jin \& Jin, 2014). All these reasons give a good suggestion to non-native English speaking countries especially in East Asia such that higher education will be limited to grow unless it is internationalized. One cost-effective way to boost internationalization would be an invitation of off-shore campuses from overseas, which also upgrades domestic higher education nationwide.

\section{References}

Altbach, P. G., Reisberg, L. \& Rumbley, L. E. (2009). Trends in global higher education: Tracking an academic revolution. A Report Prepared for the UNESCO 2009 World Conference on Higher Education.

Choi, S. (2013). CAMPUS Asia and its implications for university cooperation in Asia and EU: The Korean perspective. In Max, A., Wouters, J., Moon, W., Rhee, Y., Park, S., \& Burnay, M. (Eds). EU-Korea Relations in a Changing World. Leuven: Leuven Centre for Global Governance Studies.

EconLit. (April 2014). The American Economic Association's electronic bibliography. Retrieved from https://www.aeaweb.org/econlit/

Findlay, C. \& Tierney, W. G. (2010). Globalisation and Tertiary Education in the Asia-Pacific: The Changing Nature of a Dynamic Market. Singapore: World Scientific Publishing.

Green, C. (2015). Internationalization, deregulation and the expansion of higher education in Korea: An historical overview. International Journal of Higher Education. 4(3): 1-13. http://dx.doi.org/10.5430/ijhe.v4n3p1

IGC Foundation. (2015). Incheon Global Campus Foundation. Retrieved from http://www.igc.or.kr/en/intro/about.do

IOC. (2015). Athletes need talent - but talent alone is not enough - they also need good coaches. Coaches in Athletes. Retrieved

from 
http://www.olympic.org/content/olympic-athletes/athletes-space/entourage/coaches/?tab=coaches-qualifications

Jin, J. C. (2009). Economic research and economic growth: Evidence from East Asian Economies. Journal of Asian Economics. 20(2): 150-155. http://dx.doi.org/10.1016/j.asieco.2008.12.002

Jin, J. C. \& Cho, J. R. (forthcoming). Faculty salary at Korean universities: Does publication matter? Asian Pacific Education Review. Published online: 18 July 2015. http://dx.doi.org/10.1007/s12564-015-9382-9

Jin, J. C. \& Jin, L. (2014). On the relationship between university education and economic growth: The role of $\begin{array}{lllll}\text { professors } & \text { publication. }\end{array}$ http://dx.doi.org/10.1080/09645292.2012.697646

Schiller, A. \& Park, M. (2014). The international campus as prototype for international collaboration: South Korea's Incheon Global Campus. Global Partners in Education Journal. 4(1): 33-40.

Shin, J. C. (2015). Higher education development in Korea: Accomplishments and challenges. In Shin, J. C., Postiglione, G. A. \& Huang, F (Eds). Mass Higher Education Development in East Asia: Strategy, Quality and Challenges. Cham: Springer. http://dx.doi.org/10.1007/978-3-319-12673-9_3

Web of Science. (April 2014). Thomson Reuters Web of Science (formerly ISI Web of Knowledge). Retrieved from $\mathrm{http}: / /$ thomsonreuters.com/thomson-reuters-web-of-science/

Wilkins, S. \& Huisman, J. (2012). The international branch campus as transnational strategy in higher education. Higher Education. 64(5): 627-645. http://dx.doi.org/10.1007/s10734-012-9516-5

\section{Notes}

Note 1. The spillover effects are similar to the case of foreign direct investment (FDI) that improves domestic technologies and hence economic growth.

Note 2. The Korean government initiated globalization in the early 1990s (Green, 2015); but because of the economic crisis of 1997/98, globalization was slow down until the beginning of the new decade 2000s. In particular, the World Cup 2002 held in Korea and Japan changed the traditional Korean society in many different ways, and hence it is generally regarded as the starting point of so-called globalization in Korea.

Note 3. While the Web of Science includes SCI/SSCI publications, the EconLit includes the publications of books and working papers as well. 